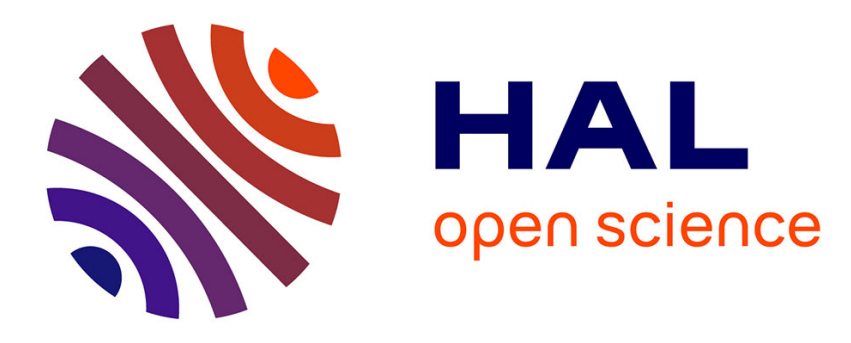

\title{
Structure of doped polyaniline - dielectric spectroscopy measurements
}

\author{
R. Diaz Calleja, E. Matveeva
}

\section{To cite this version:}

R. Diaz Calleja, E. Matveeva. Structure of doped polyaniline - dielectric spectroscopy measurements. Journal de Physique IV Proceedings, 1993, 03 (C7), pp.C7-1569-C7-1572. 10.1051/jp4:19937245 . jpa-00251883

\section{HAL Id: jpa-00251883 https://hal.science/jpa-00251883}

Submitted on 1 Jan 1993

HAL is a multi-disciplinary open access archive for the deposit and dissemination of scientific research documents, whether they are published or not. The documents may come from teaching and research institutions in France or abroad, or from public or private research centers.
L'archive ouverte pluridisciplinaire HAL, est destinée au dépôt et à la diffusion de documents scientifiques de niveau recherche, publiés ou non, émanant des établissements d'enseignement et de recherche français ou étrangers, des laboratoires publics ou privés. 


\title{
Structure of doped polyaniline - dielectric spectroscopy measurements
}

\author{
R. DIAZ CALLEJA and E.S. MATVEEVA \\ Polytechnical University of Valencia, Camino de Vera, 46071 Valencia, Spain
}

\begin{abstract}
The role of doping reagents (residual water and acid anions) in determining the electric properties of a chemically synthesized polyaniline (PANI) was studied using a dielectric spectroscopy method. Dependencies of dielectric losses and susceptibility of PANI as the functions of temperature $\left(-100 \div+100^{\circ} \mathrm{C}\right)$ and electric field frequency $(0.3 \div 30000 \mathrm{~Hz})$ were examined at it was shown that water acts as a doping impurity similar to acid anions. The model is proposed to explain the role of water in terms of adsorption of $\mathrm{H}_{2} \mathrm{O}$ molecules at nitrogen cites of PANI chain and their dissociation.
\end{abstract}

\section{INTRODUCTION}

Conductive polymeric materials and, particularly, films of polyaniline (PANI) have been intensively studied during the last decade due to perspectives of their application in galvanic sources, electrochromic displays, chemical sensors, etc. [1-4].

The electrical properties of PANI as a function of its molecular structure and various external factors are well documented in existing literature [5-7]. However, there are still some doubts about the basic mechanisms ensuring electric conductivity of PANI. It is well established that PANI may exist in three basic structures: emeraldine, pernigraniline and leicoemeraldine bases. They are transformed into corresponding salts if neutralized by acid at $\mathrm{pH}<3$. Namely salt forms of PANI exhibit high electric conduction (the highest for the emeraldine salt) [8-10]. That is why all chemical factors which are able to alter the base-acid equilibrium are potentially important in determining the conductivity of PANI and other conductive polymers. One of such factors is the presence of water molecules in the structure of PANI. The molecules of $\mathrm{H}_{2} \mathrm{O}$ are able to autodissociate thus altering the base-acid equilibrium and influencing the properties of the polymer chain in a manner similar to doping action of acid anions. Until now there is no adequate consideration of the role of water in PANI doping. The aim of the paper is to study this role and show the identity of water and acid in their influence onto the electric properties of PANI. The method of dielectric spectroscopy (DS) was used which implies a measurement of dielectric losses of the polymer at varying frequency of an electric field and temperature. DS method yields an information about electrical conductivity of polymer chains at molecular level.

\section{RESULTS AND DISCUSSION}

Samples of PANI were obtained by a chemical oxidation of heavily acidic solution $(\mathrm{pH} \propto 0$, $\mathrm{H}_{2} \mathrm{SO}_{4}$ ) of aniline (concentration $0.5 \mathrm{M} / \ell$ ) by chromium anhydride $(1 \mathrm{M} / \mathrm{l}$ ). Such-synthesized PANI films are formed of fully protonated emeraldine base, i.e. emeraldine salt according to [11]. The polyaniline/solution gel was kept at $\mathrm{pH} \approx 8$ during 24 hours and then separated from the electrolyte by multiple filtration and rinsing followed by drying at $60^{\circ} \mathrm{C}$ in evacuated atmosphere. This deprotonated PANI powder was then used as a basic material to prepare the samples with different doping levels through three-days dipping of PANI samples in $\mathrm{H}_{2} \mathrm{SO}_{4}$ solutions of various $\mathrm{pH}$

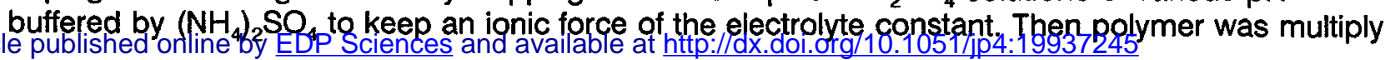


rinsed in deionized water and dried at $60^{\circ} \mathrm{C}$ in evacuated chamber during 3 days. The water content in PANI was controlled by a three-days conditioning of the samples in an ambiance with humidity $80 \%$ at $20^{\circ} \mathrm{C}$.

The dielectric spectroscopy measurements were carried out with the help of DEA-2970 analyzer by TA - Instruments. PANI powder was pressed to form $1 \mathrm{~mm}$ thick tablets with diameter of

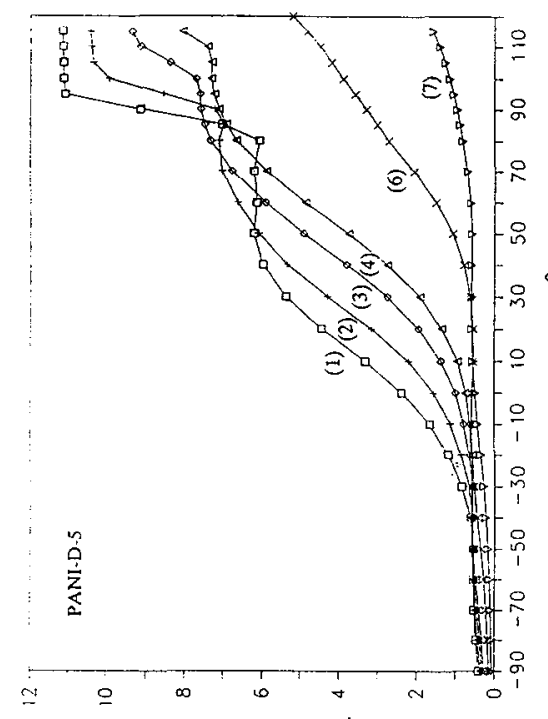

ollap UD,

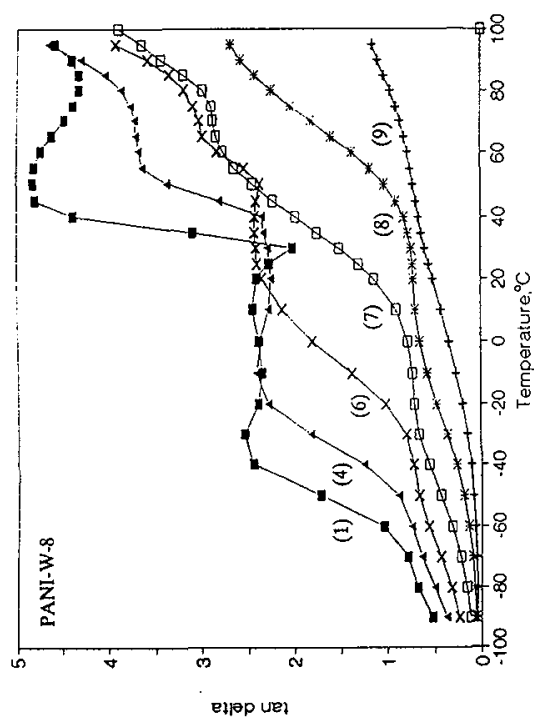

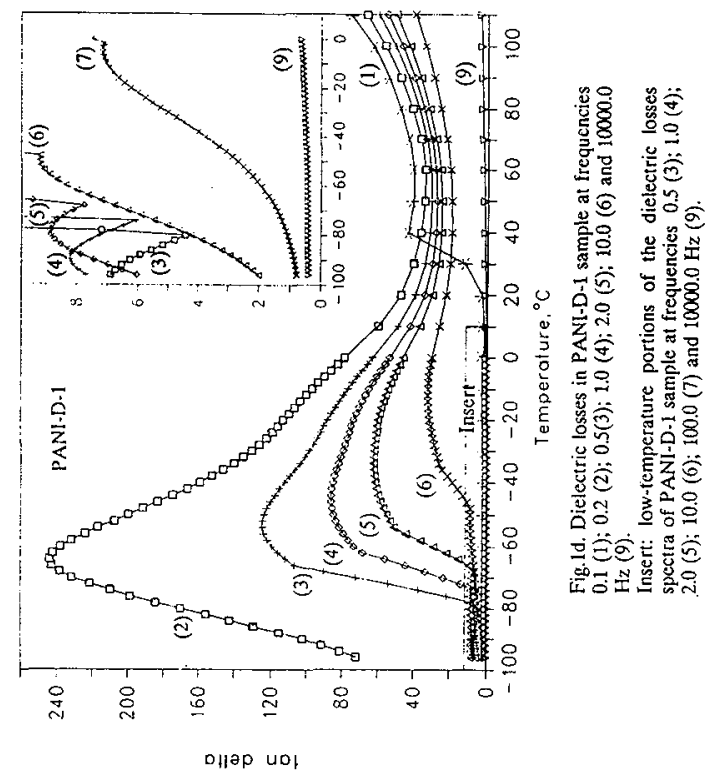

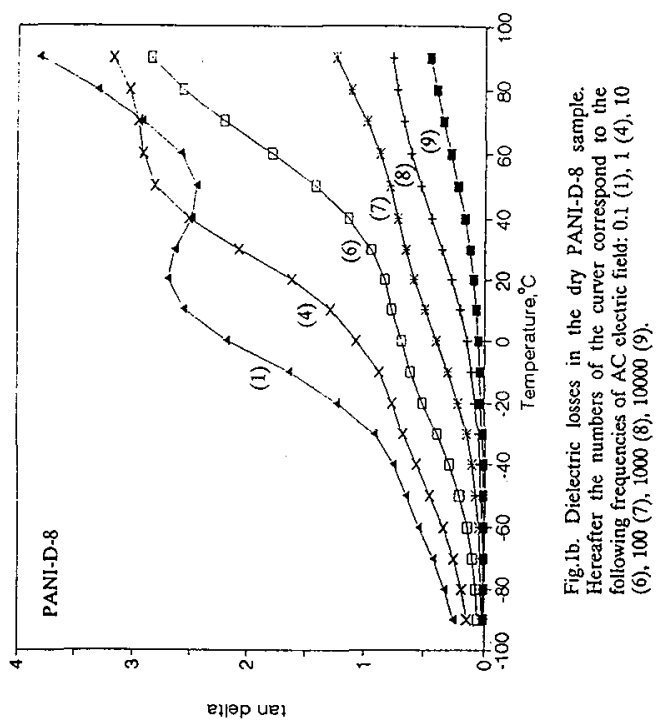

Fig.1. Dielectric losses in different samples of PANI. The numbers of the curves correspond to the following frequencies of $A C$ electric field: 0.1 (1), $0.2(2), 0.5$ (3), 1.0 (4), 2.0 (5), 10.0 (6), 100.0 (7), $1000.0(8), 10000.0(9) \mathrm{Hz}$. 
$27 \mathrm{~mm}$. The tablets were then placed into a chamber with dry nitrogen at a temperature within -100 $++100^{\circ} \mathrm{C}$ interval and polarized by $\mathrm{AC}$ voltage (amplitude $\mathrm{VV}$ ) in a frequency range $0.3 \div 30000 \mathrm{~Hz}$.

Fig.1(a-d) illustrate the dependence of dielectric losses (tan 8) on temperature and electric field frequency for different PANI samples. The uppercase letter in the sample's label shows whether it contains water or is dry (W or D, respectively), whereas digits indicate the value of $\mathrm{pH}$ of electrolyte used to dope the samples. There are two distinct regions in the tan 8 vs. temperature curves (electric field frequency is the another variable). One region corresponds to the interval of the values of $\tan 8$ from zero to $0.8+0.9$ (hereafter it will be refereed to as FT-1 region). While a temperature increases, the value of $\tan \delta$ grows for several units (FT-2 region).

The maximum value of $\tan \delta$ attainable within FT-2 zone depends on the doping level (compare Figs.1,b-1,d). Transition zone between FT-1 and FT-2 is shifted towards lower temperatures both by increasing the water content (Figs.1,a and 1,b) and the doping level (Figs.1,b-1,d). The similarity of the response of the dielectric relaxation spectra to the changes of concentration of $\mathrm{H}_{2} \mathrm{O}$ molecules and acid anions may be interpreted in terms of a similarity of a mechanism of their molecular interaction with the polymer.

The dielectric spectra of the doped and humid PANI samples (Figs.1.a, 1.c and 1.d) possess a break (FTB) that causes additional rise of the $\tan 8$ value (FT-3 region). This break is not observed for dry and undoped PANI sample (Fig.1.b). The position of FTB depends both on the temperature and electric field frequency. With increase of the doping level FTB takes place at lower temperatures and the value of $\tan \delta$ increases more (up to values of several hundreds - Fig.1.d). FT-3 region corresponds to a transition of the sample into the conductive state.

The humid (Fig.1.a) and undoped (Fig.1.c) PANI samples demonstrate essentially lower values of $\tan \delta$ at FT-3 region. So, their conductive properties are inferior, presumably due to low dissociation rate of water molecules and insufficient concentration of acid anions.

The similar response of the electric properties of PANI to variation of their doping level and water content indicates a common mechanism of interaction of water molecules and acid anions with the polymer chain. We have proposed several possible molecular structures for the PANI and their reconfiguration during interaction with water and acid anions. They are shown in the Schemes 1 and 2 (Fig.2) for the cases of undoped $(\mathrm{pH} 8$ ) and doped $(\mathrm{pH} \mathrm{1,85)} \mathrm{PANI,} \mathrm{respectively.}$

It is known that the $-\mathrm{N}=\mathrm{C}$ bond is responsible for the formation of the highly conductive emeraldine salt. We assume an interaction of water molecule with the imine nitrogen atom through the formation of hydrogen bond. This bond is formed by unshared electron couple of the nitrogen atom. As a result the neighboring atom of carbon gains some positive charge and is nucleafilly attacked by the oxygen atom of another water molecule. The hydrogen bond between the two $\mathrm{H}_{2} \mathrm{O}$ molecules completes the 6-term ring as it is shown in the Scheme 1.1.

The 6-term ring structure of the water/PANI complex corresponds to the humid samples of the polymer. It is decomposed in the case of dried PANI (through the intermediate structure 1.1,a) and finally transforms into the structure 1.2 where $\mathrm{N}$ atom is in the amine form.

The polysemiquinone structure 1.3 (2.3) may be also obtained as a result of the decomposition of the 6-term structure 1.1 assuming a redistribution of the bonds in the water molecules. The process is assisted by a generation of a positive charge (which is further delocalized in polymer chain) and formation of $\mathrm{OH}^{-}$ion stabilized by coupling with water molecule. This transformation is equivalent to autodissociacion of $\mathrm{H}_{2} \mathrm{O}$ molecules absorbed within the polymer. In the case of doped PANI (emeraldine salt) it results in regeneration of two water molecules as the charge compensation is ensured by acid anion.

The model assumes that the structure of fully protonated PANI is a product of an incomplete hydration of the imine bond $\mathrm{C}=\mathrm{N}$ of the emeraldine base through the mechanism of the acidic catalysis. The complete hydration of the imine bond is equivalent to a deprotonation of PANI, break of $\pi$-bonds in polymer chain and its transition into an insulating state.

\section{ACKNOWLEDGEMENTS}

One of the authors (E.M.) wish to acknowledge Ministry of Science and Education of Spain for awarding her a sabbatical year position. 


\section{REFERENCES}

1. J.Heinze, Synthetic Metals, 412-43(1991)2805-2823.

2. A.O.Patil, A.J.Heeger and F.Wudl Chem.Rev., 88(1988)183-200.

3. H.H.S.Zavadi, R.Laversanne, A.J.Epstein, R.K.Kohli, E.M.Scheerr and MacDiarmid A.G. Synthetic Metals, 29(1989)E439-E444.

4. E.M.Matveeva, V.P.Parkhutik, R.Diaz Calleja and J.M.Martinez-Duart J.Luminescence, 1993 (accepted for publication).

5. A.J.Epstein and A.G.MacDiarmid Macromol.Chem. Macromol.Symp, 51(1991)217.

6. Z.H.Wang, A.Ray, A.G.MacDiarmid and A.J.Epstein Phys.Rev. B 43(1991) 4373.

7. D.S.Pearson, Ph.A.Pincus, G.W.Heffner and S.J.Dahman Macromolecules 26(1993) 1570.

8. A.Ray, A.F.Richter, A.G.MacDiarmid and A.J.Epstein, Synthetic Metals, 29(1989)E151.

9. A.Alix, V.Lemoine, M.Nechtschein, J.P.Travers and. C.Menardo Synthetic Metals 29(1989)E457. 10. B.Z.Lubentsov, O.N.Timofeev and M.L.Khidekel, Synthetic Metals, 45(1991)235-240.

11. M.A.Rodrigues and M.A.de-Paoli, Synthetic Metals, 41-43(1991)2957.
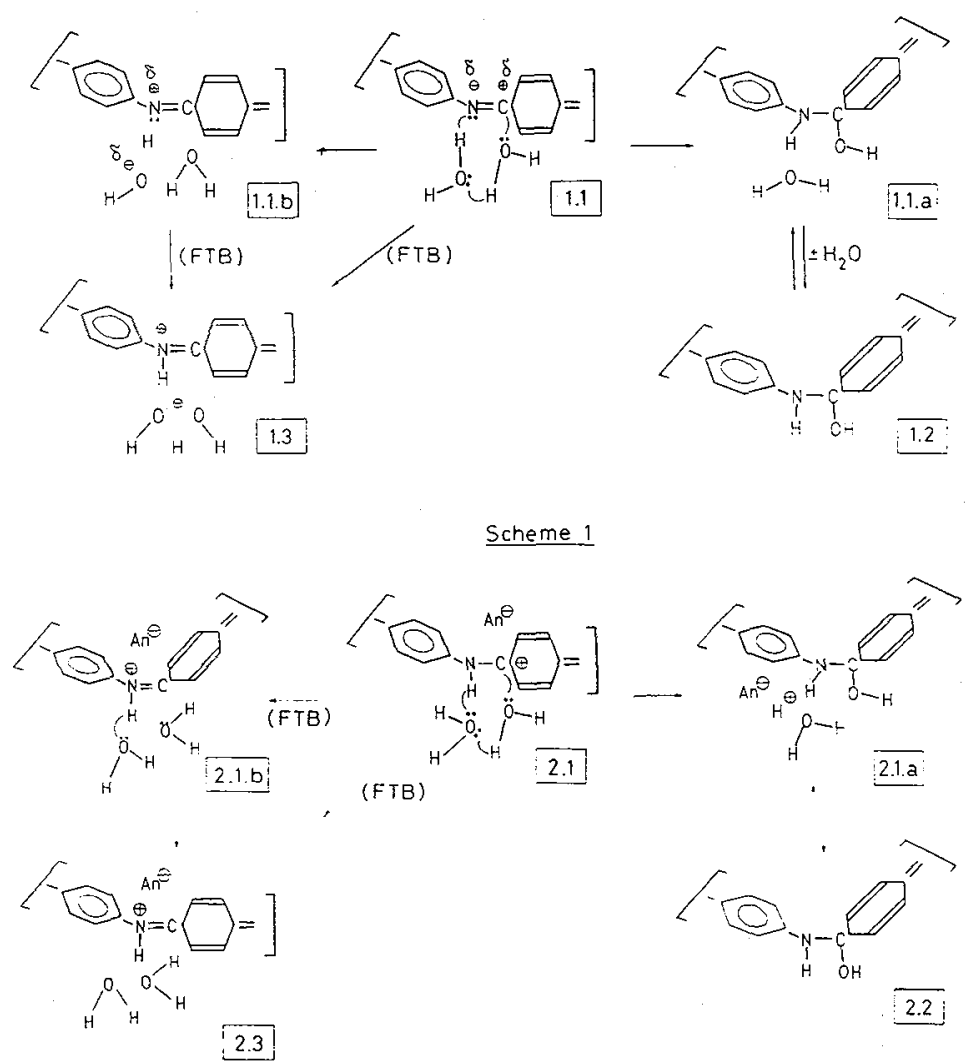

Scheme 2

Fig.2 . Possible molecular complexes formed during interaction of water molecules with PANI. Scheme 1 - for emeraldine base; Scheme 2 - for emeraldine salt. 